\title{
Permanent sequelae in sports injuries: a population based study
}

\author{
Alberto G Marchi, Daniela Di Bello, Gianni Messi, Giuseppe Gazzola
}

\begin{abstract}
Aim-To identify permanent sequelae after sports injuries in children and adolescents.

Methods-In 1985, a prospective register was drawn up of all sports related injuries reported that year by the residents of Trieste, Italy aged 6-15 years. Moderate to severe injuries (scoring $\geqslant 2$ on the abbreviated injury scale (AIS)) were the object of a longitudinal clinical study. In 1988, $30.9 \%$ of the 220 subjects enrolled had sequelae. A further follow up was undertaken in 1997.

Results-The follow up in 1997 involved 54 subjects ( 26 girls; average age 24.5 years). Subjective and objective sequelae, by now considered to be permanent, were found in $61.1 \%$, corresponding to $15 \%$ of the AIS $\geqslant 2$ injuries recorded in 1985 . The prevalence of sequelae was similar in the two sexes, in relation to the child's age at time of injury, and in the different sports practised. It was higher in relation to the severity of the lesion ( $89 \%$ of AIS 3 injuries examined, $56 \%$ of AIS 2 injuries) and to the type of lesion and its location. With regard to AIS $\geqslant 2$ injuries, permanent sequelae were found in $50 \%$ of ankle fractures, $43 \%$ of elbow fractures, $33 \%$ of leg/foot fractures, $25 \%$ of knee sprains, and $23 \%$ of ankle sprains.
\end{abstract}

Conclusions-The frequency of sequelae in sports injuries in children and adolescents is high. The risk appears to be connected to certain anatomical and functional age characteristics. Prevention strategies should include specific assessment of physical fitness and adequate follow up after the accident, particularly rehabilitation.

(Arch Dis Child 1999;81:324-328)

UO Pronto Soccorso e Primo Accoglimento, IRCCS Burlo

Garofolo, Via

dell'Istria, 65/1, 34137

Trieste, Italy

A G Marchi

G Messi

UO Ortopedia e Traumatologia, IRCCS

Burlo Garofolo

D Di Bello

G Gazzola

Correspondence to:

Professor Marchi.

email:marchi@

burlo.trieste.it

Accepted 16 June 1999 survey revealed sequelae in $30.9 \%$ of a group of 220 children followed up for three years after a moderate to severe sports injury. ${ }^{10}$ We report the follow up of these subjects after a further nine years and compare the permanent sequelae found on clinical examination 12 years after the sports injury with the sequelae found after three years. To our knowledge, this is the most prolonged longitudinal study of sports injuries in children.

\section{Methods}

Trieste is a small city $\left(212 \mathrm{~km}^{2}, 250000\right.$ inhabitants) in the north east of Italy. Resident children and adolescents aged 0-15 years (0-17 since 1997) are referred at the family's request to our institute, a mother and child hospital, which includes an emergency room and an intensive care unit, as well as all the other medical and surgical departments, with the exception of neurosurgery. Children with injuries occasionally taken to other local hospitals for adults are subsequently transferred to our hospital for care. Therefore, we think that all children in need of hospital care after injury are seen by our institute. In many cases, patient follow up continues until adulthood. These close links with the city's residents favours population studies and longitudinal surveys of injuries of children and adolescents. For the purpose of these studies, children referred to our hospital because of an "accident" but without evidence of injury ${ }^{11}$ are not considered.

As part of a prospective study, a register was made for a one year period (1 January to 31 December 1985) of all the sports related injuries sustained by the 26001 residents in the Trieste area aged between 6 and 15 years, and treated in our centre. ${ }^{12}$ Overuse sports injuries and play accidents were not included. Information collected comprised age; sex; place of residence; place of accident; circumstances of accident; whether it occurred in competition or in training, during spontaneous or supervised activity; the duration of the sports activity at the time of the accident; the location, type, and severity of the lesion measured using the abbreviated injury scale (AIS); and the type of medical care given. AIS is an injury severity rating system that has been widely used since 1971 in the motor vehicle crash investigation field. ${ }^{13}$ It assigns a single code number, on a scale of 1 (minor) to 6 (fatal), to a specific injury description. In the fourth edition (1990) over 1200 injuries are listed. ${ }^{14}$ As far as extremities are concerned, AIS 1 (minor) injuries are contusion or sprain of acromion, elbow, etc, fracture of finger; AIS 2 (moderate) injuries are knee or ankle sprains, finger amputation, carpal, tarsal, or leg uncomplicated fractures; AIS 3 (serious) injuries are open or displaced fractures of long bones, arterial 
Table 1 Sequelae after acute sports injuries in children from Trieste according to sex and age at injury registration

\begin{tabular}{|c|c|c|c|c|c|c|c|}
\hline \multirow[b]{3}{*}{ Sex and age } & \multirow[b]{3}{*}{$\begin{array}{l}A I S \geqslant 2 \text { injuries } \\
(n)\end{array}$} & \multirow{3}{*}{$\begin{array}{l}1988 \text { follow up } \\
\begin{array}{l}\text { Temporary sequelae } \\
(n)\end{array}\end{array}$} & \multicolumn{4}{|c|}{1997 follow up } & \multirow[b]{3}{*}{$p$ Value } \\
\hline & & & \multirow[b]{2}{*}{$\begin{array}{l}\text { Cases lost } \\
\text { (n) }\end{array}$} & \multirow[b]{2}{*}{$\begin{array}{l}\text { Controlled cases } \\
\text { (n) }\end{array}$} & \multicolumn{2}{|c|}{ Permanent sequelae } & \\
\hline & & & & & $n$ & $\begin{array}{l}A I S \geqslant 2 \text { injuries } \\
(\%)\end{array}$ & \\
\hline Boys & 119 & 32 & 4 & 28 & 17 & 14.3 & \\
\hline Girls & 101 & 36 & 10 & 26 & 16 & 15.8 & $0.5757 \dagger$ \\
\hline $6-10$ years & 55 & 10 & 1 & 9 & 6 & 10.9 & \\
\hline $11-13$ years & 103 & 31 & 7 & 24 & 15 & 14.6 & \\
\hline $14-15$ years & 62 & 27 & 6 & 21 & 12 & 19.4 & $0.202 \ddagger$ \\
\hline Total & 220 & 68 & 14 & 54 & 33 & 15.0 & \\
\hline
\end{tabular}

†Two sided Fisher's exact test; $\ddagger \chi^{2}$ for trend $=1.275$.

AIS $\geqslant 2$, abbreviated injury scale $\geqslant 2$ (moderate to severe).

lacerations, hand or foot amputation, tendon ruptures. The highest score for injuries to extremities (AIS 4, severe) are leg amputation or crush and pelvic crush. In our experience, AIS scoring was most suitable for rating the severity of sports related injuries in children with injuries at only one location. ${ }^{12}$ Patients with multiple injuries would be better assessed according to the injury severity score (ISS). ISS is a mathematically derived code number determined by adding the squares of the highest AIS codes in each of the three most severely injured body regions. ${ }^{13}$

One thousand and forty four subjects reported sports related injuries (rate, 4015/ 100000 residents aged $6-15$ years): 573 boys (rate 4292/100 000) and 417 girls (rate 3694/ 100 000); the percentage of moderate to severe (AIS $\geqslant 2$ ) injuries was $24.2 \%$ among the boys and $23.6 \%$ among the girls (not significant). ${ }^{12}$ All cases were followed up for as long as medical care was necessary.

A longitudinal follow up study was designed involving the 220 patients with AIS $\geqslant 2$ for lesions involving the limbs, but without lesions to the head, face, and trunk. Three years after sustaining the injury, $30.9 \%$ of the 220 patients had subjective and/or objective sequelae on clinical examination. ${ }^{10}$ The study was continued with a further clinical examination in 1997 (12 years after the initial accident) of those subjects who had had sequelae after three years; this paper examines the results of this latest examination.

Sequelae were classified either as objective (limited joint mobility, pain on pressure, axial deviations, weakness, or shortening of a limb) or subjective (pain at rest or during exercise, sense of unsteadiness, or paraesthesia). Sequelae found during the 1997 follow up were considered permanent, whereas those found in 1988 were considered to be temporary.

The permanent sequelae were analysed in relation to the child's sex and age at the time of the accident; in addition, they were analysed according to the type, location, and severity of the lesion and to the sports activity involved, as well as to the temporary sequelae present three years after the accident. Given the percentage variable of patients in the various categories with sequelae after three years subsequently lost to follow up in 1997, the permanent sequelae were also examined in relation to the total number of AIS $\geqslant 2$ lesions recorded in 1985.

\section{Results}

Of the 68 subjects who presented sequelae at the first follow up in 1988,14 were impossible to trace or did not wish to be examined. Thus, our study comprised 54 subjects ( 26 girls). The average age at the time of the second follow up was 24 years and six months (range, 18-27).

Sequelae were found in 33 of the 54 subjects examined; these were objective in 9 cases, subjective in 13 , and both objective and subjective in 11 . The subjective sequelae consisted of pain at rest (17) or during exercise (18), sense of unsteadiness (9), and paraesthesia (2); objective sequelae consisted of limited joint mobility (6), weakness (6), oedema (4), pain on pressure (3), axial deviations (2), evident scarring (2), and shortening of a limb (1).

Table 1 shows the permanent sequelae found in relation to sex and age at time of registration in 1985 , to sequelae three years later, and to the

Table 2 Sequelae after acute AIS $\geqslant 2$ sports injuries in children from Trieste according to lesion location and type

\begin{tabular}{|c|c|c|c|c|c|c|c|c|}
\hline \multirow[b]{3}{*}{ Lesion location and type } & \multirow[b]{3}{*}{$\begin{array}{l}\text { AIS } \geqslant 2 \\
\text { injuries } \\
\text { registered }(n)\end{array}$} & \multirow{3}{*}{$\begin{array}{l}1988 \text { follow up } \\
\\
\text { Temporary } \\
\text { sequelae (n) }\end{array}$} & \multicolumn{5}{|c|}{1997 follow up } & \multirow[b]{3}{*}{$p$ Value } \\
\hline & & & \multirow[b]{2}{*}{$\begin{array}{l}\text { Cases } \\
\text { lost }(n)\end{array}$} & \multirow[b]{2}{*}{$\begin{array}{l}\text { Controlled } \\
\text { cases }(n)\end{array}$} & \multicolumn{2}{|c|}{ Permanent sequelae } & \multirow[b]{2}{*}{$\begin{array}{l}\text { Risk ratio of } \\
\text { permanent } \\
\text { sequelae }\end{array}$} & \\
\hline & & & & & $n$ & $\begin{array}{l}\text { AIS } \geqslant 2 \\
\text { injuries (\%) }\end{array}$ & & \\
\hline Hand, wrist fractures & 74 & 13 & 4 & 9 & 3 & 4.1 & 0.20 & 0.001 \\
\hline Hand, wrist, elbow sprains & 26 & 3 & 1 & 2 & 0 & - & 0 & 0.018 \\
\hline Elbow fractures & 14 & 7 & _- & 7 & 6 & 42.9 & 3.27 & 0.009 \\
\hline Knee sprains & 24 & 10 & 2 & 8 & 6 & 25.0 & 1.81 & 0.22 \\
\hline Tibia fractures & 9 & 4 & 0 & 4 & 3 & 33.3 & 2.34 & 0.14 \\
\hline Ankle fractures & 4 & 2 & 0 & 2 & 2 & 50.0 & 3.48 & 0.11 \\
\hline Foot fractures & 6 & 2 & 0 & 2 & 2 & 33.3 & 2.30 & 0.22 \\
\hline Ankle sprains & 43 & 18 & 3 & 15 & 10 & 23.2 & 1.79 & 0.10 \\
\hline Others & 20 & 9 & 4 & 5 & 1 & 5.0 & 0.31 & 0.32 \\
\hline Total & 220 & 68 & 14 & 54 & 33 & 15.0 & - & - \\
\hline
\end{tabular}

${ }^{\star}$ Compared with all the other injuries combined.

AIS $\geqslant 2$, the abbreviated injury scale $\geqslant 2$ (moderate to severe); Others, fractures of knee, shoulder, clavicle. 
Table 3 Sequelae after acute AIS $\geqslant 2$ sports in children from Trieste according to sports activity

\begin{tabular}{|c|c|c|c|c|c|c|c|c|}
\hline \multirow[b]{3}{*}{ Activity } & \multirow[b]{3}{*}{$\begin{array}{l}\text { AIS } \geqslant 2 \\
\text { injuries } \\
\text { registered }(n)\end{array}$} & \multirow{3}{*}{$\begin{array}{l}1988 \text { follow up } \\
\text { Temporary } \\
\text { sequelae ( } n \text { ) }\end{array}$} & \multicolumn{6}{|c|}{1997 follow up } \\
\hline & & & \multirow[b]{2}{*}{$\begin{array}{l}\text { Cases } \\
\text { lost }(n)\end{array}$} & \multirow[b]{2}{*}{$\begin{array}{l}\text { Controlled } \\
\text { cases }(n)\end{array}$} & \multicolumn{2}{|c|}{ Permanent sequelae } & \multirow[b]{2}{*}{$\begin{array}{l}\text { Risk ratio of } \\
\text { permanent } \\
\text { sequelae }\end{array}$} & \multirow[b]{2}{*}{$p$ Value } \\
\hline & & & & & $n$ & $\begin{array}{l}\text { AIS } \geqslant 2 \\
\text { injuries }(\%)\end{array}$ & & \\
\hline School physical education & 43 & 14 & 3 & 11 & 8 & 18.6 & 1.31 & 0.48 \\
\hline Basketball & 27 & 13 & 4 & 9 & 6 & 22.2 & 1.34 & 0.43 \\
\hline Football & 43 & 13 & 3 & 10 & 6 & 13.9 & 0.77 & 0.66 \\
\hline Downhill skiing & 34 & 6 & 1 & 5 & 5 & 14.7 & 0.83 & 0.81 \\
\hline Volleyball & 14 & 4 & - & 4 & 2 & 14.3 & 0.90 & 0.89 \\
\hline Rollerskating & 15 & 5 & 1 & 4 & 2 & 13.3 & 0.84 & 0.79 \\
\hline Handball & 7 & 3 & - & 3 & 1 & 14.3 & 0.95 & 0.96 \\
\hline Others (18 activities) & 37 & 10 & 2 & 8 & $3+$ & 21.6 & 0.49 & 0.31 \\
\hline Total & 220 & 68 & 14 & 33 & 33 & 15.0 & - & - \\
\hline
\end{tabular}

${ }^{\star}$ Compared with all the other sports combined.

+Wrestling two of three; motor cross one of one.

AIS $\geqslant 2$, abbreviated injury scale $\geqslant 2$ (moderate to severe).

total number of cases with AIS $\geqslant 2$ lesions. There was a similar distribution of permanent sequelae among the two sexes, whereas sequelae at three years had been more frequent among the girls, although not significantly so. ${ }^{10}$ One possible explanation is that more girls were lost to follow up in 1997 than boys. With regard to age, permanent sequelae appeared to be more frequent for injuries sustained by children under 10, whereas temporary sequelae had been seen more frequently above 10 years $(p<0.05) .{ }^{10}$ This could occur because of the high number of cases of older children with temporary sequelae who were lost to follow up. In fact, in relation to the total number of AIS $\geqslant 2$ lesions, permanent sequelae were more frequent with increasing age, although not significantly.

Permanent sequelae were found in nine of 10 AIS 3 lesions examined (seven of seven fractures, two of three sprains) and in 26 of 45 AIS 2 lesions (nine of 20 fractures, 15 of 23 sprains, two of two other lesions). The type and location of the lesions was particularly significant (table 2). Sequelae were particularly frequent after fractures of the elbow, tibia, ankle, and foot, and knee and ankle sprains, which confirmed the earlier results of the study in 1988.

Table 3 shows the influence of the specific type of sport practised. Permanent sequelae were more frequent after accidents involving downhill skiing, school physical education, and basketball than after other sports, but this was not significant. These results differ from the previous study, in which temporary sequelae were more frequent than the average also in accidents while playing handball and rollerskating, and less frequent in downhill skiing. ${ }^{10}$ There appeared to be no relation between sequelae and the sport practised.

Table 4 summarises the results of the longitudinal study and the prevalence rates among the Trieste population of sports related injuries

Table 4 Sports related injuries and sequelae in children from Trieste 1985-97

\begin{tabular}{lrl}
\hline & $n$ & $\begin{array}{l}\text { Rate/100 000 residents } \\
\text { (6-15 years old) }\end{array}$ \\
\hline Sports injuries registered (1985) & 1044 & 4015 \\
AIS $\geqslant 2$ injuries (1985) & 250 & 961 \\
Temporary sequelae (1988 follow up) & 68 & 261 \\
Permanent sequelae & 33 & 126 \\
\hline
\end{tabular}

AIS $\geqslant 2$, abbreviated injury scale $\geqslant 2$ (moderate to severe). and their sequelae. It is worth noting the high prevalence of permanent sequelae resulting from the sports related injuries occurring in one year alone.

\section{Discussion}

The follow up of individuals who have sustained an injury can be useful because it provides information about: (1) the long term complications and sequelae, and (2) the effectiveness of the care provided and the possible need for rehabilitation programmes. ${ }^{15}$ The difficulty of carrying out longitudinal follow up studies $^{16}$ has meant that attention has been focused upon the more serious, life threatening accidents that can result in disability, such as multiple trauma, and injuries to the head, face, and viscera..$^{151718}$

Isolated lower limb injuries are rarely life threatening but can be associated with prolonged periods of disability and handicap. ${ }^{9}$ Especially in children, it is important to bear in mind the possible effect of the injury on musculoskeletal structures, ${ }^{15}{ }^{19}$ as well as the adverse effects that even a minor disability can have on the adolescent's self image ${ }^{1120}$ and on normal everyday activities. ${ }^{4}$

However, there are far fewer follow up studies of sports related injuries in children than studies of an epidemiological and clinical nature. They tend to be less serious than similar injuries in adults, ${ }^{61-23}$ and are rarely fatal, ${ }^{24}$ but among older children and adolescents, sports accidents are more frequent and serious than other types of accident. ${ }^{425-30}$

In the 6-15 year age group studied in Trieste, when fatalities were excluded, sports accidents were three times more frequent and serious than road accidents, and among children over 10 years, they were second in terms of frequency, but first in terms of severity, compared with accidents in the home ${ }^{31}$; a quarter of the sports accidents recorded in 1985 were moderate to severe. ${ }^{12}$ Follow up three years later revealed that $30.9 \%$ of these 220 subjects had sequelae, ${ }^{10}$ a rate two to three times higher than that reported by other authors one to three years after the lesion. ${ }^{346-8}$ This difference was probably because the severity of the lesion was one of the inclusion criteria for the follow up.

Extending the study over the long term revealed that over $60 \%$ of these subjects still 
had sequelae 12 years after the accident. Leaving aside the 14 subjects with temporary sequelae lost to follow up, $15 \%$ of the 220 subjects who sustained moderate to severe sports injuries in 1985 had permanent sequelae. This prevalence rate, which relates to the accidents occurring in one year alone, is higher than that reported by Barker et al in a study of accident related disability in the $0-16$ age group. ${ }^{9}$ At 23 years of age, $6.3 \%$ of the 287 subjects admitted to hospital with a sports injury reported a permanent disability, with a similar incidence in men and women: only accidents in the workplace and on the roads caused a higher rate of sequelae. In 2208 other subjects not hospitalised, $1.9 \%$ of the boys and $4.4 \%$ of the girls reported disabilities with a frequency inferior only to that of road accidents. Comparison between our results and those of Barker is possible only with regard to the more serious lesions, because in Trieste these patients were hospitalised; we have no data regarding the minor lesions because follow up was not performed. However, it should be stressed that in the study of Barker et al, more than half of the disabilities in the boys and two thirds of those in the girls resulted from minor lesions receiving ambulatory care.

The results of our study show that the most important factors influencing the likelihood of permanent sequelae are the characteristics and severity of the lesion. The child's sex, the age at the time of the accident, and the type of activity involved were not significant.

The influence of the severity of the lesion is clear: there was a higher prevalence of permanent sequelae after AIS 3 lesions than after AIS 2 lesions, despite the fact that the AIS is not a significant predictor of sequelae, as we have already reported in a previous study. ${ }^{32}$

Apart from the severity, it was the type and location of the lesion that most influenced the likelihood of sequelae. At the anatomical level, one example is the elbow fracture in which the bone callus of the humerus occupies the olecranon fossa, thus obstructing the capitulum of the ulna. At the functional level, mention should be made of the ankle sprains in which unsteadiness can cause subsequent re-injuries resulting in permanent disability.

The absence of any relation between sequelae and the sports activity practised indicated that it is the child's specific anatomical and functional characteristics that influence the frequency of sequelae.

The sequelae resulting from sports accidents merit our attention because even if they are not seriously disabling they can still impair everyday life and activity. ${ }^{4} 7$ We did not try to measure the impairment caused by the permanent sequelae that we found in our subjects. We know that subjective reporting has an important role to play in defining disability, ${ }^{16}{ }^{33}$ and that in the study of Barker et al it was the subjects themselves who reported the disability resulting from the accident.

In conclusion, it would seem wise to reconsider the idea of the benign nature of sports accidents in children. ${ }^{4}$ The gradual increase in supervised sports activity in many countries makes it necessary to adopt a specific approach for children who practise sports, beginning with the preliminary assessment of physical fitness and aptitude ${ }^{34}$ and strict adherence to the guidelines for properly supervised sports activity. ${ }^{35}$ As much attention should be paid to rehabilitating a child after a sports injury as to rehabilitating an adult athlete. ${ }^{36-38}$ Longitudinal follow up studies of sports related injuries are another essential aid to prevention. The risk of sequelae seem to be connected more to the anatomical and functional characteristics of the child than to the specific sport practised. It is the paediatrician's task to ensure that the schools and sports clubs where children do supervised physical activity are as well informed as possible about the factors involved.

Part of this paper was presented at the fourth world conference on injury prevention and control, Amsterdam, 17-20 May 1998.

1 Robertson LS. Injury epidemiology. New York: Oxford University Press, 1992

2 World Health Organisation. WHO annual report. Geneva: WHO, 1994.

3 Ungerholm S, Gierup J, Lindsjö U, Magnusson A. Skiing injuries in children: lower leg fractures. Int $\mathcal{F}$ Sports Med 1985;6:292-7.

4 Tursz A, Crost M. Sports-related injuries in children. A study of their characteristics, frequency and severity, with comparison to other types of accidental injuries. Am 7 Sports Med 1986;14:294-9.

5 Häyrinen-Immonen R, Sane J, Perkki K, Malmström M. A six-year follow-up study of sports-related dental injuries in six-year follow-up study of sports-related dental injuries in
children and adolescents. Endod Dent Traumatol 1990;6: 208-12.

6 Olkkonen S, Lahdenranta U, Slätis P, Honkanen R. Bicycle accidents often cause disability. An analysis of medical and social consequences of nonfatal bicycle accidents. Scand $\mathcal{F}$ Soc Med 1993;21:98-106.

7 Yacoubovitch J, Lelong N, Cosquer M, Tursz A. Étude epidémiologique des séquelles d'accidents à l'adolescence. Arch Pediatr 1995;2:532-8.

8 Shorter NA, Jensen PE, Harmon BJ, Mooney DP. Skiing injuries in children and adolescents. F Trauma 1996;40: 997-1001

9 Barker M, Power C, Roberts I. Injuries and the risk of disability in teenagers and young adults. Arch Dis Child 1996;75:156-8.

10 Messi G, Gazzola G, Renier S, Glavina A, Marchi AG. Lo sport, il bambino e gli incidenti. III Gli esiti a distanza. Minerva Pediatr 1990;42:173-8.

11 Tursz A. Collection of data on accidents in childhood: problems of method. In: Manciaux M, Romer CJ, eds. Accidents in childhood and adolescence. Geneva: WHO, 1991:39-56.

12 Marchi AG, Renier S, Messi G, Gazzola G. Lo sport, il bambino e gli incidenti. I Epidemiologia generale. Minerva Pediatr 1988;40:151-6.

13 Abbreviated injury scale, 1980 revision. Morton Grove, IL: American Association for Automotive Medicine, USA.

14 Yates DW. Scoring systems for trauma. BMF 1990;301: 1091-3.

15 Kaiser G. Some important aspects of follow up in the traumatized child. Proceedings of the first international meeting on pediatric intensive care. Padova, 19-21 October 1989. Published in Italian in: Chiandetti L, Da Dalt L, Pettenazzo A, Zacchello F, eds. Emergenze in pediatria. Bologna: Monduzzi Ed, 1991:95-111.

16 Tiret L, Nicaud V, Maguin P, Hatton F. Incapacity of accidental origin in young people. In: Manciaux M, Romer CJ, eds. Accidents in childhood and adolescence. Geneva: WHO, eds. Accidents

17 Frutiger A, Ryf C, Bilat C, et al. Five years' follow up of severely injured ICU patients. F Trauma 1991;31:1216-25.

18 Henderson JM, Browning DG. Head trauma in young athletes. Med Clin North Am 1994;78:289-303.

19 Mayer PJ. Lower limb injuries in childhood and adolescence. In: Micheli LJ, ed. Pediatric and adolescent sports medicine. Boston: Little, Brown and Co, 1984:80-106.

20 Weinberger JL, Kantor M. Possible sequelae of trauma and somatic disorder in early life. Int $\mathcal{F}$ Psychiatry Med 1976;7: $337-50$

21 Ungerholm S, Engkvist O, Gierup J, Lindsjö U, Balfors B. Skiing injuries in children and adults: a comparative study from an 8-year period. Int $\mathcal{F}$ Sports Med 1983;4:236-40.

22 Goldberg B, Rosenthal PP, Robertson LS, Nicholas JA. Injuries in youth football. Pediatrics 1988;81:255-61.

23 Lee AJ, Garraway WM. Epidemiological comparison of injuries in school and senior club rugby. Br $\mathcal{F}$ Sports Med 1996;30:213-17. 
24 Avery JG, Harper P, Ackroyd S. Do we pay too dearly for our sport and leisure activities? An investigation into fatalities as a result of sporting and leisure activities in England and Wales, 1982-88. Public Health 1990;104: 417-23.

25 Nathorst-Westenfelt JAR. Environmental factors in childhood accidents. A prospective study in Göteborg, Sweden. Acta Pediatr Scand Suppl 1982;291:1-75.

26 Gallagher SS, Guyer B, Kotelchuck M, et al. A strategy for the reduction of childhood injuries in Massachusetts: SCIPP. N Engl f Med 1982;307:1015-19.

27 Sheps SB, Evans GD. Epidemiology of school injuries: a 2-year experience in a municipal health department. Pediatrics $1987 ; 79: 69-75$.

28 Sahlin Y. Sport accidents in childhood. Br $\mathcal{F}$ Sports Med 1990;24:40-4.

29 Nolan T, Penny M. Epidemiology of non-intentional injuries in an Australian urban region; results from injury. $\mathcal{F}$

30 Hammaström A, Janlert U. Epidemiology of school injuries in the northern part of Sweden. Scand F Soc Med 1994;22: in the nor
31 Marchi AG, Messi G, Casini P, Renier S. Studio Trieste degli incidenti pediatrici. II. Analisi dei fattori di rischio degli incidenti del bambino. Minerva Pediatr 1986;38:311-18.

32 Casini P, Messi G, Marchi AG. Studio Trieste degl incidenti pediatrici. III. Sulla predittività degli esiti a distanza. Minerva Pediatr 1987;39:471-4.

33 Hutchinson T. The classification of disability. Arch Dis Child 1995;73:91-3.

34 Rowland TW. Preparticipation sports examination of the child and adolescent athlete: changing views of an old ritual. Pediatrician 1986;13:3-9.

35 American Academy of Pediatrics. Committee on sports medicine. Recommendations for participation in competitive sports. Pediatrics 1988;81:737-9.

36 Ekstrand J, Gillequist J, Lilijedarl SO. Prevention of soccer injuries: supervision by doctor and physiotherapist. $A m \mathcal{F}$ Sports Med 1983;11:116-20.

37 Micheli LJ. Sports injuries in children. Ann Nestle 1986;44: $20-6$

38 Stanitski CL. Common injuries in preadolescent and adolescent athletes. Recommendations for prevention. adolescent athletes. Recom
Sports Med 1989;7:32-41. 